\title{
REVIEW
}

\section{CREATION AND VALIDATION OF Q-DIO, AN INSTRUMENT FOR RATING THE QUALITY OF NURSING DOCUMENTATION - LITERATURE REVIEW}

\author{
Dagmar Šerková1, Jana Marečková ${ }^{2,3}$ \\ ${ }^{1}$ Department of Nursing and Midwifery, Faculty of Medicine, University of Ostrava, Czech Republic (student) \\ ${ }^{2}$ Department of Anthropology and Health Education, Faculty of Education, Palacký University Olomouc, Czech Republic \\ ${ }^{3}$ The Czech Republic (Middle European) Centre for Evidence-Based Healthcare: A Joanna Briggs Institute Centre of \\ Excellence, Czech Republic
}

Received July 20, 2017; Accepted September 23, 2017. Copyright: This is an open access article distributed under the terms of the Creative Commons Attribution International License (CC BY). http://creativecommons.org/licenses/by/4.0/

\begin{abstract}
Aim: To summarize relevant information on the creation and validation of the Quality of Nursing Diagnoses, Interventions and Outcomes (Q-DIO) assessment instrument. Design: A literature review. Methods: To search for studies, the first two steps of a standard evidence-based healthcare approach were used: 1) formulation of a search question and 2) structured documented search including assessment of the relevance of abstracts and full text of studies to the search question and inclusion criteria. In relevant studies, the level of evidence was evaluated using the Joanna Briggs Institute categories. Results: Out of 212 results of two-step search in scholarly databases and grey literature sources, only three literature resources were relevant. The newly developed Q-DIO instrument was assessed by its authors using content and face validation (100\% consensus of experts and 88.25\% agreement), intrarater $(\mathrm{r}=0.98 ; \mathrm{p}<0.0001 ; \kappa=0.95 ; \mathrm{p}<0.0001)$ and interrater reliability $(\mathrm{r}=0.99 ; \mathrm{p}<0.0001$, $\kappa=0.95 ; \mathrm{p}<0.0001)$ and internal consistency of the concepts of the instrument $(\mathrm{C} \alpha=0.83 ; \mathrm{C} \alpha=0.98 ; \mathrm{C} \alpha=0.90 ; \mathrm{C} \alpha=0.99)$. Item analysis was carried out to determine both difficulty and discriminative validity of the items. Conclusion: Q-DIO was by the authors marked as valid assessment instrument by its authors. However, since the assessed instrument items are formulated without identifying currently valid NNN nomenclature terminology, they should be specified prior to a particular assessment of the quality of nursing documentation.
\end{abstract}

Keywords: item analysis, literature review, Q-DIO, quality of documentation, reliability, validation.

\section{Introduction}

Rapid advances in modern technology and increasing costs of healthcare worldwide have led to the development of nursing terminology and documentation, including the organization of nurses' work using the nursing process method (Marečková, Jarošová, 2005; Müller-Staub et al., 2007a). The outcomes of patient needs assessment with a nursing diagnostic conclusion, followed by planning and provision of targeted nursing care with specification of data for evaluation of its effectiveness in the patient, are recommended to be properly documented. Wang, Hailey and Yu (2011) justify the necessity for proper records by considering nursing documentation a communication tool for exchanging professional information. They have been joined by authors stressing the fact that the accuracy of nursing care records means that they are conclusive and reviewable (Paans et al., 2010; Linch

Corresponding author: Dagmar Šerková, Department of Nursing and Midwifery, Faculty of Medicine, University of Ostrava, Styllabova 19, Ostrava, Czech republic; email: dasa.serkova@volny.cz et al., 2012) and it is crucial for patient safety (Paans, Müller-Staub, 2013). Nursing documentation may also be used for legal purposes, allocation of financial resources, quality of care assessment (Paans et al., 2010) or as a source of research data (Wang, Hailey, $\mathrm{Yu}, 2011)$. In the nursing community, the yield and effectiveness of documentation is frequently discusses; that is why issues arise that are related to the assessment of its quality. Instruments for assessing nursing documentation were developed, for instance, by Ziegler: "Criteria for Evaluating the Quality of the Nursing Process - ZCEQNP", Müller-Staub: the tool "Documentation Diagnostics DD" for measuring the quality of nursing diagnoses formulated in free style (Müller-Staub et al., 2009), Björvell, Thorell-Ekstrand and Wredling: "Cat-chIng" for evaluating nursing documentation in the Swedish setting (Björvell, Thorell-Ekstrand, Wredling, 2000) and a team led by Lunney: "Scale to Measure Accuracy of Nurses Diagnoses" (Marini, Chaves, 2011). According to Müller-Staub et al. (2009), the above instruments are aimed at assessing nursing diagnoses but they do not evaluate their 
connection with nursing interventions and outcomes of care in a patient. Other examples are the "NoGa" instrument (Nordström, Gardulf, 1996) or "The Quality of Nursing Diagnosis - QOD" (Florin, Ehrenberg, Ehnfors, 2005). However, according to Paans (2010), they only assess the quality of nursing diagnoses but not documentation as a whole involving a series of interconnected steps in the nursing process (Müller-Staub et al., 2009; Paans et al., 2010). This motivated Müller-Staub to create an instrument called "Quality of Nursing Diagnoses, Interventions and Outcomes, Q-DIO" (Table 4) for evaluating the quality of comprehensive documentation with records of nursing diagnoses, interventions and results of nursing care in a patient. With repeated use in a healthcare facility, the Q-DIO is a means of continuous monitoring of the quality of documentation; it may also be used for auditing.

\section{Aim}

The review aimed at summarizing available relevant information on the creation and validation of the instrument "Quality of Nursing Diagnoses, Interventions and Outcomes, Q-DIO" by MüllerStaub.

\section{Methods}

\section{Design}

A literature review.

\section{Search question}

To meet the objective, a search question was formulated using the $\mathrm{P}-\mathrm{I}-(\mathrm{C}-$ not applicable $)-\mathrm{O}$ components with additional synonymous and related terms (Table 1). The search question was as follows: "What procedures were used for the Quality of Nursing Diagnoses, Interventions and Outcomes,
Q-DIO (P) to validate and test the reliability of the instrument (I) and with what outcomes $(\mathrm{O})$ ?"

\section{Search strategy}

The standard search strategy was applied as recommended by evidence-based healthcare methodology (Marečková et al., 2015). To conduct a database search, a two-step search strategy was prepared based on the search question. The primary search terms, as an input to the development of the search strategy, were P - Problem: Q-DIO; I - Intervention: validation, measurement of reliability; $\mathrm{C}$ - Comparison: not applicable and O - Outcomes: validity, reliability. To increase the search sensitivity, synonyms and related terms were added to the primary search terms using the Boolean operator OR (Table 1). To increase the search specificity for both steps, partial results for the $\mathrm{P}$ - I - O components were connected using the Boolean operator AND (Table 2). Based on findings from the first step of the search, the keywords were adapted for the second step (see details in Table 1). For both steps of the search, the following strategy was used: title/abstract, search period 1/2000-6/2017, no language restrictions.

\section{Sources}

The following databases were searched: MEDLINE (the PubMed interface), CINAHL Plus with Full Text, Wiley Online Library, Bibliographia Medica Čechoslovaca (the Medvik interface), OpenGrey a multidisciplinary European database on grey literature, and the web search engines MedNar and Google Scholar. Grey literature resources were included based on the Joanna Briggs Institute (JBI) standard search recommendations to increase the thoroughness of search results.

Table 1 Synonymous and related terms for the $\mathrm{P}-\mathrm{I}-\mathrm{O}$ components

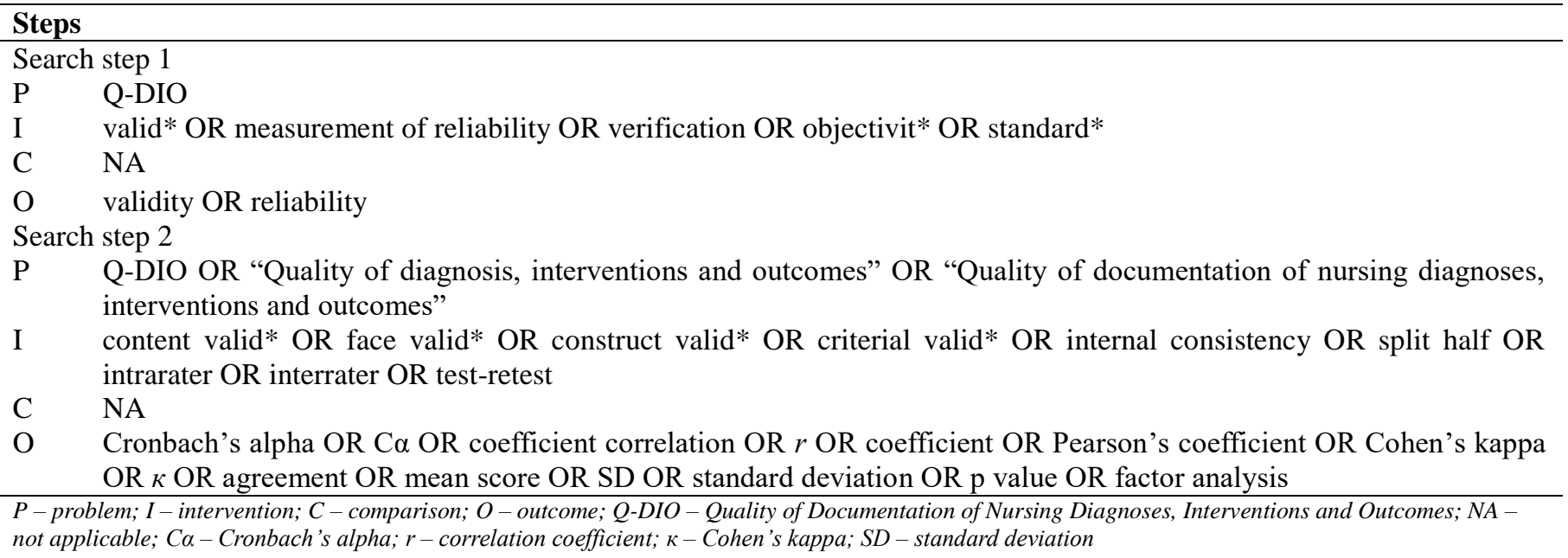


Table 2 Search results

\begin{tabular}{|c|c|c|c|c|}
\hline \multirow{3}{*}{$\begin{array}{l}\text { Results } \\
\text { Search step } 1\end{array}$} & \multicolumn{3}{|c|}{ Total } & \multirow[t]{2}{*}{ operator AND } \\
\hline & & 96 resources & & \\
\hline & results for $\mathrm{P}(\mathrm{n})$ & results for I (n) & results for $O(n)$ & search results (n) \\
\hline Medline & 12 & $1,379,967$ & 165,816 & 6 \\
\hline CINAHL & 6 & 262,209 & 41,958 & 4 \\
\hline Wiley & 11 & 391,785 & 38,939 & 4 \\
\hline BMC & 3 & 10,322 & 798 & 0 \\
\hline OpenGrey & 0 & 0 & 308 & 0 \\
\hline MedNar & 60 & 108 & 57 & 40 \\
\hline Google Scholar & 150 & 17,600 & $1,330,000$ & 42 \\
\hline \multirow[t]{2}{*}{ Search step 2} & & 116 resources & & \\
\hline & results for $\mathrm{P}(\mathrm{n})$ & results for I (n) & results for $O(n)$ & search results (n) \\
\hline Medline & 12 & 42,519 & 870,026 & 5 \\
\hline CINAHL & 6 & 17,288 & 244,536 & 4 \\
\hline Wiley & 605 & 21,271 & 585,198 & 27 \\
\hline BMC̆ & 4 & 234 & 5,135 & 0 \\
\hline OpenGrey & 8 & 1,477 & 234,792 & 0 \\
\hline MedNar & 20 & 20 & 20 & 20 \\
\hline Google Scholar & 9 & 17,600 & 26,700 & 60 \\
\hline
\end{tabular}

\begin{tabular}{|c|c|c|c|}
\hline \multicolumn{4}{|c|}{ Levels of evidence in QUANTITATIVE research } \\
\hline \multirow[t]{5}{*}{ of evidence } & $\begin{array}{l}\text { experimental } \\
\text { studies }\end{array}$ & $\begin{array}{l}\text { level 1a } \\
\text { level 1b } \\
\text { level 1c } \\
\text { level 1d }\end{array}$ & $\begin{array}{l}\text { systematic reviews of randomized controlled trials } \\
\text { systematic reviews of randomized controlled trials } \\
\text { and other study designs } \\
\text { randomized controlled trials } \\
\text { pseudo-randomized controlled trials }\end{array}$ \\
\hline & $\begin{array}{l}\text { quasi- } \\
\text { experimental } \\
\text { studies }\end{array}$ & $\begin{array}{l}\text { level 2a } \\
\text { level 2b } \\
\text { level 2c } \\
\text { level 2d }\end{array}$ & $\begin{array}{l}\text { systematic reviews of quasi-experimental studies } \\
\text { systematic reviews of quasi-experimental and other } \\
\text { lower study designs } \\
\text { quasi-experimental prospectively controlled studies } \\
\text { pre-test, post-test or retrospective control group } \\
\text { studies }\end{array}$ \\
\hline & $\begin{array}{l}\text { observational- } \\
\text { analytic studies }\end{array}$ & $\begin{array}{l}\text { level 3a } \\
\text { level 3b } \\
\text { level 3c } \\
\text { level 3d } \\
\text { level 3e }\end{array}$ & $\begin{array}{l}\text { systematic reviews of comparable cohort studies } \\
\text { systematic review of comparable cohort and other } \\
\text { lower study designs } \\
\text { cohort studies with control groups } \\
\text { case - controlled studies } \\
\text { observational studies without control groups }\end{array}$ \\
\hline & $\begin{array}{l}\text { observational- } \\
\text { descriptive } \\
\text { studies }\end{array}$ & $\begin{array}{l}\text { level 4a } \\
\text { level } 4 b \\
\text { level } 4 c \\
\text { level } 4 d\end{array}$ & $\begin{array}{l}\text { systematic reviews of descriptive studies } \\
\text { cross-sectional studies } \\
\text { case series } \\
\text { case studies }\end{array}$ \\
\hline & $\begin{array}{l}\text { expert opinion, } \\
\text { bench research }\end{array}$ & $\begin{array}{l}\text { level } 5 \mathbf{a} \\
\text { level } 5 \mathbf{b} \\
\text { level } 5 \mathbf{c}\end{array}$ & $\begin{array}{l}\text { systematic reviews of expert opinion } \\
\text { expert consensus } \\
\text { single expert opinion, bench research }\end{array}$ \\
\hline \multicolumn{4}{|c|}{ Levels of evidence in QUALITATIVE research } \\
\hline & level 1 & \multicolumn{2}{|c|}{ qualitative systematic review } \\
\hline & level 2 & \multicolumn{2}{|c|}{ qualitative synthesis } \\
\hline of evidence & level 3 & \multicolumn{2}{|c|}{ qualitative study (primary research) } \\
\hline & level 4 & \multicolumn{2}{|c|}{ systematic review of expert opinion } \\
\hline & level 5 & \multicolumn{2}{|c|}{ literature review of qualitative research, expert opinion } \\
\hline
\end{tabular}

Figure 1 Levels of evidence in quantitative and qualitative research (Klugar, 2015; Marečková et al., 2015) 


\section{Selection of studies}

In both search steps, the selection of results was based on removing duplicates and assessing the relevance of abstracts to the search question represented by $\mathrm{P}-\mathrm{I}-\mathrm{O}$ (Table 1) and inclusion criteria. For relevant abstracts, full texts of articles were retrieved and, once again, carefully assessed for relevance.

Inclusion criteria - only primary studies relevant to the search question (i.e. the $\mathrm{P}-\mathrm{I}-\mathrm{O}$ components) were included in the literature review; the minimum JBI levels of evidence were $4 b$ for quantitative evidence and 3 for qualitative evidence (Fig. 1). Together with the Cochrane Collaboration, the JBI is one of the global leaders in evidence-based practice (Marečková, 2016).

Exclusion criteria - excluded were studies assessing the quality of nursing documentation not using the terminology set of NANDA International, Nursing
Interventions Classification and Nursing Outcomes Classification (NNN), studies on other types of nursing documentation and studies not relevant to the search question, including literature reviews.

\section{Results}

\section{a) Search results}

In the first step of the search, 96 resources were identified (14 abstracts in scholarly databases and 82 in grey literature sources). After assessment of their relevance to the inclusion and exclusion criteria (see the Methods section), three of them were classified as relevant. Two of them were full texts of studies indexed in scholarly databases and the remaining one was a dissertation included in the grey literature category. In the second step, 116 resources were identified (36 in scholarly databases and 80 in grey literature sources). Gradually, 114 documents were

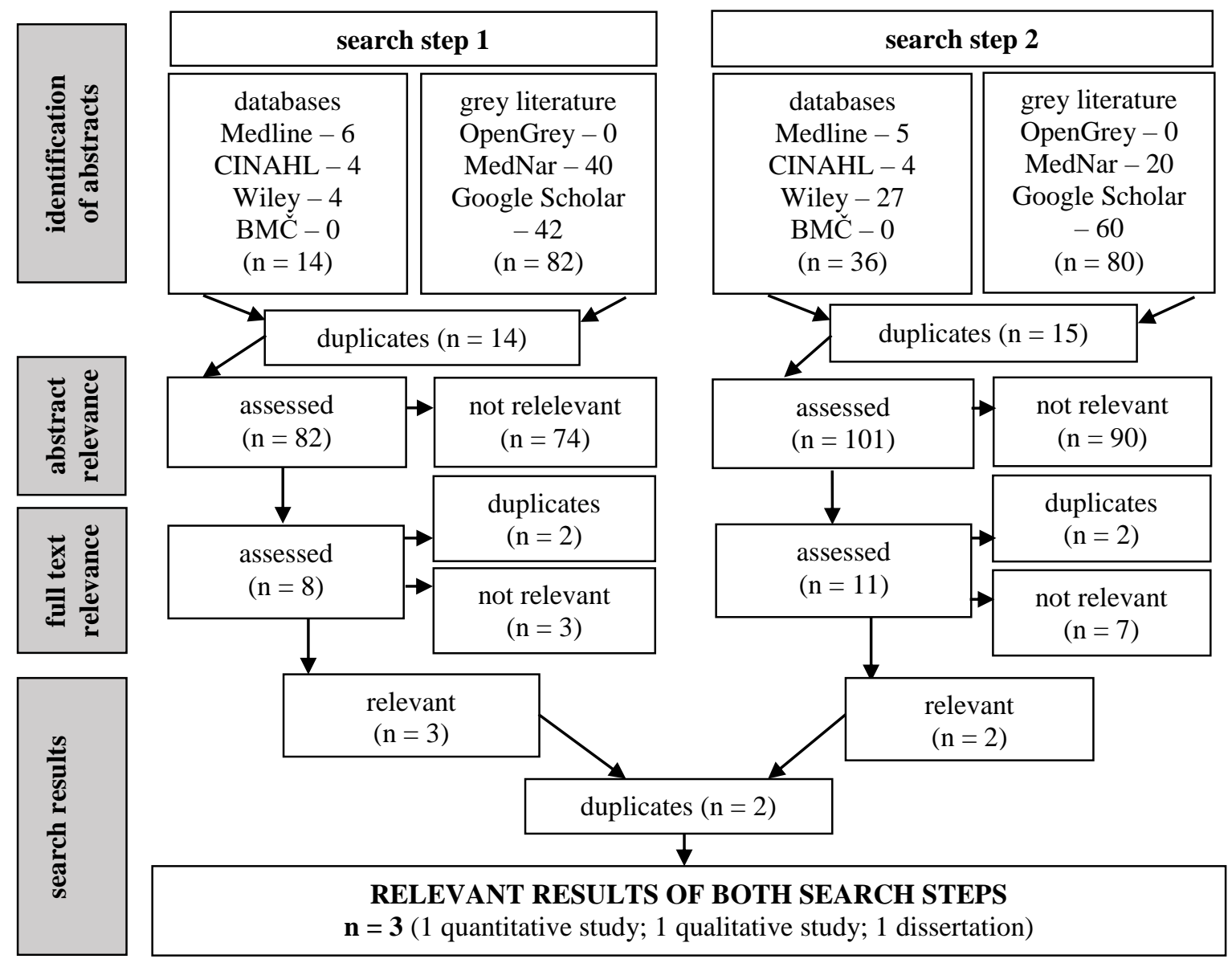

Figure 2 Flow diagram of the literature search 
excluded during assessment of relevance. The second step yielded two studies, both being duplicates of search step one results. Thus, the final result of the search was three full texts. The search process is shown in Fig. 2.

b) Assessment and description of relevant search results

Since the dissertation Evaluation of the implementation of nursing diagnostics: a study on the use of nursing diagnoses, interventions and outcomes in nursing documentation (Müller-Staub, 2007b) presented a series of 6 published studies, an assessment was performed to find out whether they contained additional information to that obtained by the literature search. Two of them (Müller-Staub et al., 2008a; Müller-Staub et al., 2009) were identical to the articles retrieved from scholarly databases. Their texts were part of Chapters 4 and 5 (p. 69-84 and 85-98, respectively) of the dissertation and in July 2007, the time of the dissertation defense, they were classified as "in press" after they had been through peer review and accepted for publication. Texts of another three chapters were not relevant to the search question. Chapter 6 presented an implementation study of the effect of an educational intervention for nurses on the quality of nursing documentation evaluated with the Q-DIO instrument (Müller-Staub, 2007a). As this issue was not a component of formulating the search question and the objective of the literature review, the article was excluded at that step of the study.

Full texts of the relevant studies were subjected to an assessment of the level of evidence. The JBI categories were used for evaluating both quantitative and qualitative studies (Fig. 1). Obtained from the full texts was information concerning the design, objective, methods and results, as summarized in Table 3.

Authors' note: When producing systematic reviews as secondary research results, prior to extraction of data for quantitative meta-synthesis or qualitative meta-aggregation, a standardized evaluation of the methodological quality of a series of attributes is also conducted using some of JBI or Cochrane instruments (Klugarová et al., 2015). For literature reviews, such specific assessments are irrelevant and thus were not carried out.

\section{Review text}

The following section presents available information on the creation and validation of the newly constructed instrument Q-DIO. Since the two-step search failed to identify other relevant studies in either scholarly databases or sources of grey literature, information from two journal articles published in 2008 and 2009 was used.

\section{a) Creation of the $Q-D I O$ instrument}

The authors participating in the development of the Q-DIO (Müller-Staub et al., 2009) stated that the theoretical framework for creating the instrument was the concept and contents of the NNN nursing classification systems, that is, the NANDA International, Nursing Interventions Classification and Nursing Outcomes Classification, and the nursing process. Prior to defining the reference criteria for measuring the quality of documentation, Müller-Staub et al. conducted two literature reviews. A 2001 review was performed to find instruments for measuring the quality of documentation of nursing diagnosis and a 2006 review aimed to find instruments that also measure the quality of nursing interventions and patient outcomes.

Based on the defined theoretical framework and the above literature reviews, the instrument development was initiated. Four concepts of the new instrument were delineated and for each of them, reference criteria for measuring the quality of nursing documentation were formulated and operationalized into items of the instrument. The authors selected a Likert-type scale to measure the items and elaborated methods for assessing the level of quality of documented phenomena. The first concept of the instrument, called "Nursing diagnoses as process", was constructed to assess records of nursing information on the patient's current condition. The second concept, "Nursing diagnoses as product", measures the quality of documenting nursing diagnosis. The third concept, "Nursing interventions" is concerned with interventions related to nursing diagnoses. The fourth concept is called "Nursingsensitive patient outcomes".

The structure of the instrument and methods for the use of scales (Müller-Staub et al., 2008a; MüllerStaub et al., 2009) were designed as follows:

Concept 1 - Nursing diagnoses as process: 11 items, a 2-0 Likert-type subscale (score 2 is used for comprehensive documentation, score 1 for a partially documented item and score 0 means not documented);

Concept 2 - Nursing diagnoses as product: 8 items, a 4-0 Likert-type subscale (score 4 for correct formulation of a nursing diagnosis, including the name, characteristics and related or risk factors, score 3 for its partially correct formulation, score 2 for correct formulation of the name of a nursing diagnosis only, score 1 for partially correct 
formulation of the name of a nursing diagnosis and score 0 when nursing diagnoses are not formulated);

Concept 3 - Nursing interventions: 3 items, a 4-0 Likert-type subscale (score 4 for identification of correct formulation, score 3 for documenting partially correct formulation, score 2 for stating correct formulation, score 1 for partially correct formulation and score 0 for no documented intervention);
Concept 4 - Nursing-Sensitive Patient Outcomes: 7 items, a 4-0 Likert-type subscale (scores identical to those for Concept 3 ).

The Q-DIO instrument was constructed with three key items, namely Item 12 (Concept 2), Item 20 (Concept 3) and Item 25 (Concept 4). Based on those, the quality of other items in that concept may be predicted as they are directly related (Müller-Staub et al., 2008a; Müller-Staub et al., 2009).

Table 3 Description of relevant studies

\begin{tabular}{|c|c|c|c|}
\hline Study & Research design & $\begin{array}{l}\text { JBI level of } \\
\text { evidence }\end{array}$ & Objective(s) stated in the study \\
\hline \multirow[t]{3}{*}{$\begin{array}{l}\text { Müller-Staub } \\
\text { et al. (2009) }\end{array}$} & $\begin{array}{l}\text { qualitative - interpretative } \\
\text { phenomenological analysis }\end{array}$ & 3 & \\
\hline & \multicolumn{3}{|c|}{ Methods and results stated in the study } \\
\hline & \multicolumn{3}{|c|}{$\begin{array}{l}\text { specification of the theoretical framework, developing reference criteria and assessment indicators, developing } \\
\text { assessment methods for Likert-type scales, } \\
\text { methods: a focus group of } 8 \text { experts (opinions how } 29 \text { items represent the domains of } 4 \text { concepts of the } \\
\text { instrument, opinions on the relevance and precision of the instrument) } \\
\text { results: } 100 \% \text { consensus of the experts, conclusions: the Q-DIO captures important aspects of measurements } \\
\text { and is consistent with the common terminology standard } \\
\text { pilot testing of interrater reliability - agreement of raters of nominal variables in } 1 \text { documentation (yes/no for } \\
\text { item usability, \% of agreement with } 88.25 \% \text { agreement between the experts) } \\
\text { conclusion: to subject the instrument for validity and reliability testing }\end{array}$} \\
\hline \multirow[t]{3}{*}{$\begin{array}{l}\text { Müller-Staub } \\
\text { et al. (2008a) }\end{array}$} & $\begin{array}{l}\text { observational - descriptive cross- } \\
\text { sectional study }\end{array}$ & $4 \mathrm{~b}$ & $\begin{array}{l}\text { to determine internal consistency, intra- and interrater } \\
\text { reliability and to perform item analysis focusing } \\
\text { on frequency of endorsement as a function of the } \\
\text { difficulty of the items and on discrimination validity } \\
\text { of items }\end{array}$ \\
\hline & \multicolumn{3}{|c|}{ Methods and results stated in the study } \\
\hline & \multicolumn{3}{|c|}{ 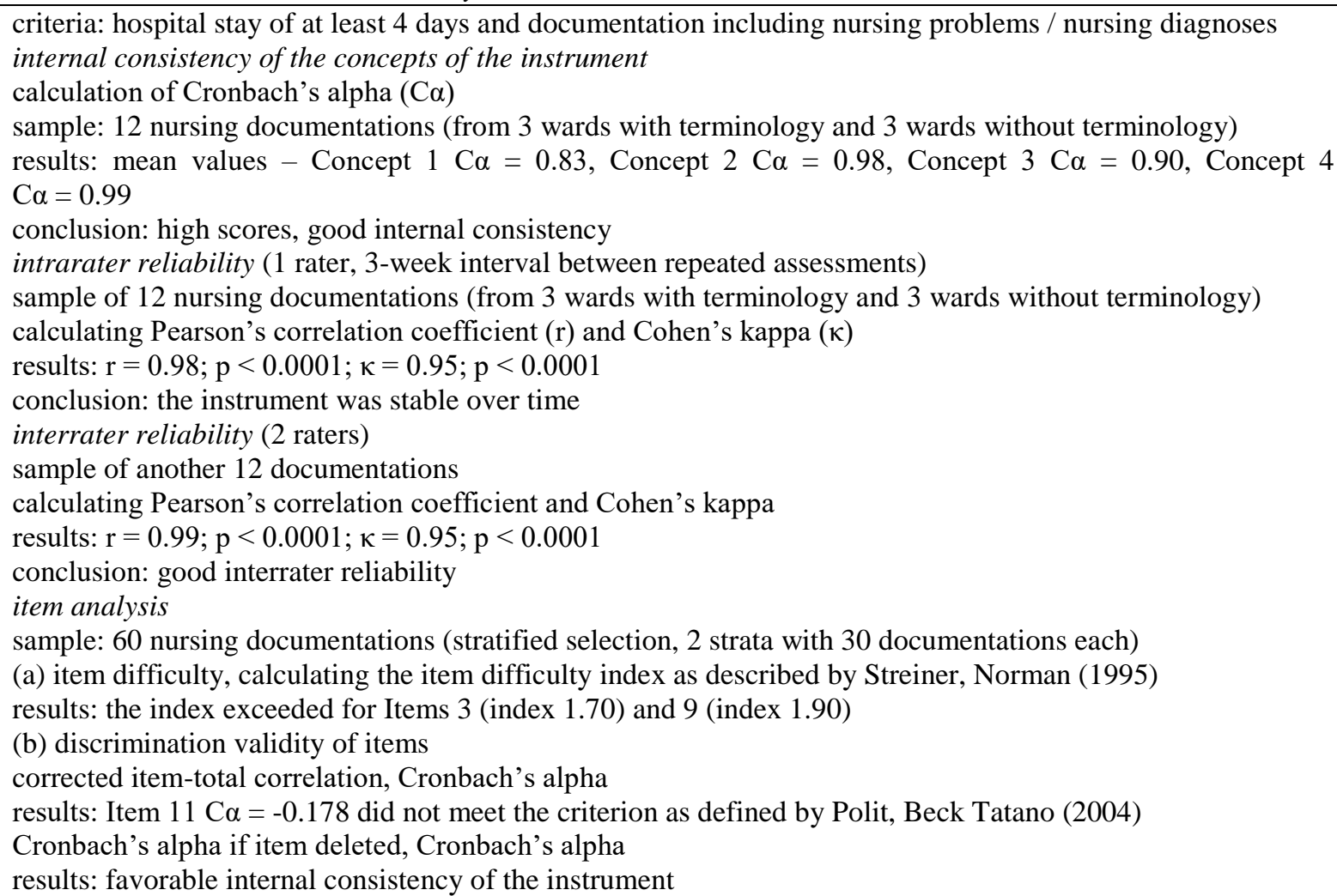 } \\
\hline
\end{tabular}


Table 4 Quality of Nursing Diagnoses, Interventions and Outcomes (Q-DIO) instrument (Müller-Staub et al., 2009)

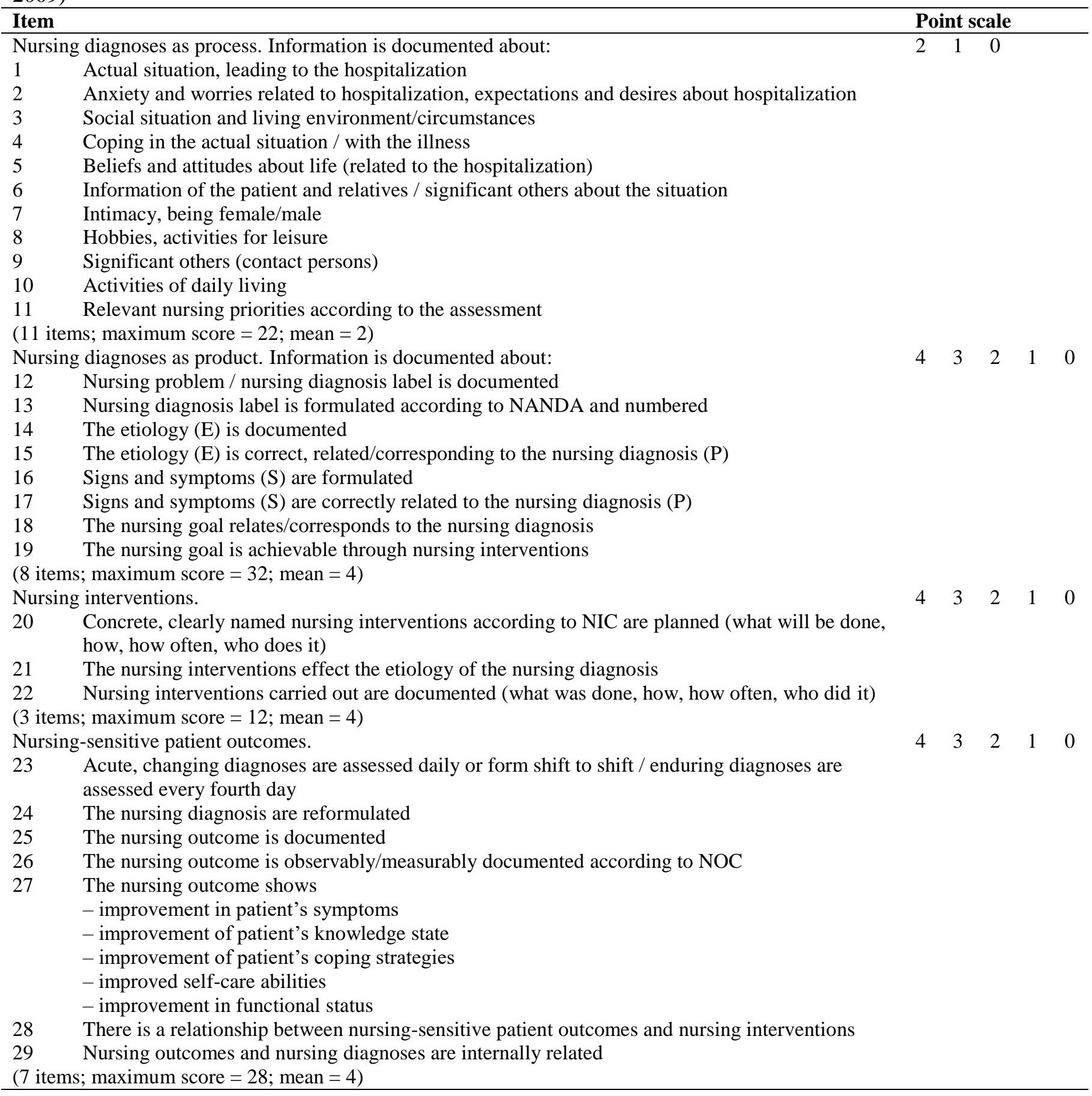

\section{b) Assessment of $Q-D I O$ validity}

Gradual validity and reliability tests were performed in two of the included studies (Müller-Staub et al., 2008a; Müller-Staub et al., 2009). Müller-Staub et al. (2009) reported that the face validity of the newly constructed instrument was evaluated using a consensus model in a focus group comprising 8 experts (nurses with a master's degree responsible for training and implementation of nursing diagnoses, interventions and outcomes in practice). The expert opinions were obtained using two lists of questions with topics for discussion of the focus group members to assess the relevance and precision of the items in all four Q-DIO concepts. The result was $100 \%$ agreement of the experts claiming that the Q-DIO captured the important aspects to be measured and was in concordance with common standards of terminology. According to the authors (MüllerStaub et al., 2009), pilot testing of interrater reliability/agreement was performed for the same 
nursing documentation. Using the Q-DIO instrument, eight experts independently analyzed the quality of nursing documentation of one patient. The agreement (yes/no) of raters for all 29 items of the instrument was analyzed and the proportion of agreement was calculated. The results showed $88.25 \%$ agreement between the experts.

Additionally, the instrument was tested in Bürgerspital Solothurn near Bern, Switzerland. The tests focused on internal consistency of the four concepts of the instrument, its intrarater and interrater reliability and item analysis to determine (a) the frequency of endorsement as a function of the difficulty of the items and (b) the discrimination validity of items (Müller-Staub et al., 2008a). The authors stated that nursing documentations for item analysis was selected using a stratified random sample technique. Two strata of nursing documentations were chosen, one $(n=30)$ from three wards where standardized terminology was not implemented and the other one $(n=30)$ from three wards using standardized terminology. Documentations of both strata $(n=60)$ were manually written, that is, the electronic form of documentation was not used. For internal consistency and reliability testing, the sample $(\mathrm{n}=12)$ was created by random selection of 3 wards with documentation using terminology and 3 with documentation without terminology. From those, a sample $(\mathrm{n}=12)$ of documentations for intrarater reliability testing was purposefully selected (based on two criteria: at least a 4-day hospital stay and nursing problems/diagnoses recorded in documentation). For interrater variability tests, a new sample $(\mathrm{n}=12)$ was produced. All documentations in the samples were anonymized and passed on to external raters to be assessed using the Q-DIO instrument. Study by author Müller-Staub states that internal consistency of the Q-DIO concepts was verified by calculating Cronbach's alpha $(\mathrm{C} \alpha)$ with the following mean values: $\mathrm{C} \alpha=0.83$ for Concept $1, \mathrm{C} \alpha=0.98$ for Concept 2, $\mathrm{C} \alpha=0.90$ for Concept 3 and $\mathrm{C} \alpha=0.99$ for Concept 4. Without the key Items 12, 20 and 25 (see Creation of the Q-DIO instrument), the mean values were still high, being $\mathrm{C} \alpha=0.98$ for Nursing diagnoses as product, $\mathrm{C} \alpha=0.98$ for Nursing interventions and $\mathrm{C} \alpha=0.99$ for Nursing-sensitive patient outcomes; the value for Nursing diagnoses as process was not stated. Based on the Cronbach's alpha values, the authors reported that the internal consistency of the instrument was good (MüllerStaub et al., 2008a) without specifying the term.

To test intrarater reliability, nursing documentations $(\mathrm{n}=12)$ were repeatedly evaluated by the same rater using the Q-DIO at a time interval of three weeks.
Pearson's correlation coefficient (r) and Cohen's kappa $(\kappa)$ were calculated. Based on the results $(\mathrm{r}=0.98 ; \mathrm{p}<0.0001$ and $\kappa=0.95 ; \mathrm{p}<0.0001)$, the authors stated that the instrument was stable over time.

To test interrater reliability of the instrument, two raters were involved. The Q-DIO was tested in another sample $(\mathrm{n}=12)$ of documentations (6 with standardized nursing terminology and 6 without standardized terminology). Once again, Pearson's correlation coefficient and Cohen's kappa were calculated. The results $(r=0.99 ; p<0.0001$ and $\kappa=0.95 ; \mathrm{p}<0.0001)$ showed good interrater variability of the Q-DIO instrument.

Item analysis of the sample $(\mathrm{n}=60)$ of documentations was aimed at determining both difficulty and discriminative validity of the items. According to methods described by Streiner and Norman (1995), the indexes of item difficulty should have been less than 1.6 for Concept 1 and less than 3.2 for the other concepts (Streiner, Norman, 1995). Higher indexes were identified for two items of Q-DIO Concept 1, namely Item 3 (Social situation and living environment/circumstances) and Item 9 (Significant others / contact persons) with indexes of item difficulty of 1.70 and 1.90, respectively. Discriminative validity was tested using two approaches. Corrected item-total correlation is a correlation coefficient between the scores of an item and the mean of the scores of all other items of the instrument. The $\mathrm{C} \alpha$ values for individual items were interpreted according to Polit and Beck Tatano (2004) recommending that they should exceed 0.3. For 28 items of the instrument, $\mathrm{C} \alpha$ values met the above criterion; the only exception was Item 11 (Relevant nursing priorities according to the assessment) from Concept 1 with $\mathrm{C} \alpha=-0.178$ not fulfilling the criterion. The other approach was to calculate Cronbach's alpha if item deleted. Both tests showed that the internal consistency of the instrument remained good. The presented assessment of the Q-DIO revealed that three items were problematic, namely Concept 1 Items 3,9 and 11. Yet the authors of the primary validation study decided to leave these three items in the instrument, stating that Concept 1 ensures completeness of nursing documentation and these were not key items (Müller-Staub et al., 2008a).

Based on the results of both validation studies, the authors concluded that the tested Q-DIO instrument is applicable in practice to assess the quality of nursing documentation and that further testing of the instrument in the setting of other healthcare facilities is desirable. 


\section{Limitations of the literature review}

The text of the literature review was limited by a small number of studies found. However, relevant resources were identified using elaborate, structured and methodology-based search in both scholarly databases and grey literature. The search strategy was constructed so that it was able to find as many available studies with rigorous validation of the Q-DIO instrument as possible. Despite this very precise search strategy, only three studies were retrieved.

\section{Discussion}

As the authors of the Q-DIO recommended that the instrument is further tested in healthcare facilities, a structured search was performed before writing the Discussion section to identify research papers concerned with its use. Both scholarly and grey literature databases identical to those described in the Methods section were searched. The search period was limited to January 2000 to June 2017; no language restrictions were imposed. The search identified full texts in English, German, Spanish and Portuguese. Duplicates of English versions were excluded. The search resulted in 14 relevant full texts written in English, of which eight were found in scholarly databases and six in grey literature sources, namely ACENDIO conference proceedings. Müller-Staub was the first author of two relevant texts and a co-author of another eight ones; four papers were prepared by other experts.

The retrieved texts show that the Q-DIO was used to collect data for quasi-experimental research projects (prior to and after an education program intervention), adaptation to other languages, a mixed quantitative and qualitative research design, comparison of the quality of nursing documentation with various terminology and as an incentive to initiate work on developing an internationally valid assessment instrument. The studies analyzing Q-DIO scores prior to and after various types of education programs included three from Switzerland (MüllerStaub et al., 2007a; Müller-Staub et al., 2008b; Bruylands et al., 2013), one from Brazil (Nomura, da Silva, Almeida, 2016), one from Nigeria (Odutayo et al., 2013) and two from Italy (Baudino, Vernassa, 2013; Baudino et al., 2015). Four teams were concerned with adapting the English version of the Q-DIO to other languages. Their texts provided information about adaptations to Brazilian Portuguese (Linch et al., 2012; Linch et al., 2015), Spanish (Mateos-García et al., 2015) and French (Seen, Lötscher, Müller-Staub, 2015). In 2013, the development of another instrument that was followed by Q-DIO was launched, with the ambition of the authors to achieve its international validity. Primary information about it was published in the ACENDIO (Paans, Müller-Staub, 2013), but the follow-up outputs were not identified until June 2017. A mixed quantitative and qualitative research design was used to assess the quality of nursing records of patients with acute pain after total hip replacement in Switzerland (Zanon, Gralher, Müller-Staub, 2015). The patient sample whose documentation was evaluated using the Q-DIO-Pain, an adapted version of the instrument, also participated in a quantitative questionnaire survey. The qualitative dimension of the research was represented by semi-structured interviews with five patients and a focus group discussion with nurses. The outcomes provided the authors with a more comprehensive view of the quality of nursing documentation. Another interesting study was that comparing the quality of documentation using NANDA and NIC terminology with ICNP terminology conducted by a Brazilian team in 2017 (Rabelo-Silva et al.).

Since the present literature review aimed at summarizing information on validity of the instrument, studies were selected that tested its validity and reliability. Those included projects concerned with adapting the instrument to other languages. First, cross-cultural adaptation of the Q-DIO into Brazilian Portuguese was conducted by Linch et al. (2012). Their study followed guidelines for the process of cross-cultural adaptation as described by Beaton et al. (2000): (1) two translations from the original language to the target language produced by two translators whose mother tongue is the target language, (2) synthesis of the translated versions and consensus of the translators, (3) back translation by two translators with the source language as their mother tongue, (4) consensus of authors of the adaptation and producing a prefinal version of the adapted instrument and (5) testing the proposed version and possible further adjustments including retests (Beaton et al., 2000). In order to keep the meaning of the original text, Q-DIO Items 5, $9,20,23,26$ and 29 (Table 4) underwent semantic or cultural modification when producing the Portuguese versions. Additionally, the instrument was adapted so that all items were assessed on a three-point Likerttype scale. The Portuguese version of the Q-DIO was pilot-tested in a sample of 40 nursing records of patients after cardiac surgery (20 electronic records with NANDA-I terminology and 20 paperbased records without terminology) in two centers. Linch et al. (2012) assessed internal consistency of the instrument by calculating Cronbach's alpha to 
obtain the following mean values: $\mathrm{C} \alpha=0.88$ for Concept 1, $\mathrm{C} \alpha=0.95$ for Concept 2, $\mathrm{C} \alpha=0.66$ for Concept 3, $\mathrm{C} \alpha=0.97$ for Concept 4 and $\mathrm{C} \alpha=0.97$ for the entire instrument. (Linch et al., 2012) The results are consistent with those reported by the QDIO authors (Müller-Staub et al., 2008a). The reliability of the Portuguese version was assessed by calculating the index of item difficulty and discriminative validity was evaluated by applying corrected item-total correlation and Cronbach's alpha if item deleted. The results were presented in tables and suggested a high level of reliability of the adapted instrument.

The 2012 piloted version of the Q-DIO was subjected to further, more thorough testing of validity in 2015 .

The Portuguese version was used to assess 180 records from two centers in Brazil $(\mathrm{n}=120)$ and one center in the USA $(n=60)$. The centers had different approaches to records: Center $1(n=60)$ electronic records and standardized nursing terminology; Center $2(n=60)$ used paper-based records, no standardized terminology, Portuguese; and Center $3(\mathrm{n}=60)$ electronic records and no standardized terminology. Internal consistency was evidenced by high mean Cronbach's alpha values $(\mathrm{C} \alpha \geq 0.70$ at all three centers): $\mathrm{C} \alpha=0.70, \mathrm{C} \alpha=0.89$ and $\mathrm{C} \alpha=0.82$ for Centers 1, 2 and 3, respectively. Corrected item-total correlation and Cronbach's alpha if item deleted were also calculated. The authors of this research state that the study highlighted the problematic results of handwritten documentation, which often does not apply standard nursing terminology. Additionally, the study by Linch et al. (2015) analyzed intra- and interrater reliability by means of intraclass correlation coefficients (ICCs). Stability of the instrument was confirmed, with ICCs of $0.74,0.64$ and 0.85 (interrater reliability) and $0.70, \quad 0.68$ and 0.82 (interrater reliability) for Centers 1, 2 and 3, respectively. The article also describes assessment of discriminative validity among the documentation groups by analysis of variance with Tukey's post-hoc test, with significant differences being identified between the centers. Out of the highest possible score of 58 points, Center 1 achieved a mean of $36.8 \pm 4.5$ [95\% confidence interval (CI), 35.6-37.9], Center 2 $11.5 \pm 6.2(95 \% \mathrm{CI} ; 9.9-13.1)$ and Center 3 $31.2 \pm 5.3$ (95\% CI, 29.8-32.6). Thus, the highest score was observed in a center using electronic records and standardized terminology. The authors concluded that the psychometry test of the Q-DIO using records in Brazil and the USA showed good reliability (internal consistency and stability) of the instrument. They underlined that the instrument is able to discriminate the quality of various forms of nursing documentation.
Other materials presenting adaptation of the Q-DIO to Spanish and French were published in 2015 ACENDIO conference proceedings and were relatively short. Mateos-García et al. (2015) partly described a questionable reduction of the instrument to 14 items and pilot validation results while Seen, Lötscher, Müller-Staub (2015) provided brief information about a French version and the intention of testing the instrument in the home care setting.

\section{Conclusions}

The published information on the Q-DIO assessment instrument suggest the following:

The Q-DIO was identified as a valid assessment instrument by its authors. Subsequently, only one thorough validation was published that followed adaptation of the instrument to Brazilian Portuguese in 2012 and 2015.

Given the terminological freedom, that is, the fact that the instrument does not specify the items assessed in accordance with the current NANDA International, Nursing Interventions Classification a Nursing Outcomes Classification (NNN terminology), the assessed terms should be defined before the instrument is used. If more raters are to assess the quality of documentation at the same time, first, they should have a discussion to reach a consensus about working with the NNN terminology and methods for assessing the accuracy of nursing records.

Further research on the Q-DIO should be based on a mixed quantitative and qualitative design.

\section{Ethical aspects and conflict of interest}

The literature review was prepared in accordance with the ethical principles of publishing and the authors are not aware of any possible conflict of interest.

\section{Author contribution}

After mutual agreement, the authors claim that their contribution to the literature review was $50 \%$. Concept and design (DŠ, JM), analysis and interpretation of data (DŠ, JM), drafting of the manuscript (DŠ, JM), critical revision of the manuscript (DŠ, JM) and approval of the final manuscript.

\section{References}

Baudino M, Vernassa A. Computer-assisted nursing care process: a retrospective study. In: Sheerin F, Sermeus W, Ehrenberg A, editors. E-health and nursing innovating for the future: $9^{\text {th }}$ European conference of ACENDIO. Ireland: 
Dublin; 2013. p. 345-348. Available from: http://www.acendio.net/members/proceedings/ACENDIO201 3.pdf

Baudino M, Vernassa A, De Pieri C, Massano S, Contini S, Boarino G, Brociero MG. Assessment and care plans based on standardized and computerized language: a retrospective study. In: Sheerin F, Sermeus W, Ehrenberg A, editors. Ehealth and nursing - knowledge for patient care: $10^{\text {th }}$ European conference of ACENDIO. Ireland: Dublin; 2015. p. 293-296. Available from: http://www.acendio.net/members/proceedings/ACENDIO201 5.pdf

Beaton DE, Bombardier C, Guillemin F, Ferraz MB. Guidelines for the process of cross-cultural adaptation of selfreport measures. Spine. 2000;25(24):3186-3191.

Björvell C, Thorell-Ekstrand I, Wredling R. Development of an audit instrument for nursing care plans in the patient record. Quality in Health Care. 2000;9(1):6-13.

Bruylands M, Paans W, Hediger H, Müller-Staub M. Effects on the quality of the nursing care process through an educational program and the use of electronic nursing documentation. International Journal of Nursing Knowledge. 2013;24(3):163-170.

Florin JF, Ehrenberg A, Ehnfors M. Quality of nursing diagnoses: evaluation of an educational intervention. International Journal of Nursing Terminologies and Classifications. 2005;16(2):33-43.

Klugar, M. Systematická review ve zdravotnictví. Olomouc: Univerzita Palackého v Olomouci; 2015. (in Czech)

Klugarová, J, Klugar, M, Marečková, J, Hájek, M. Methodology of systematic review development I: the effectiveness of hyperbaric oxygen therapy on mortality in adults with craniotrauma. Czech and Slovak Neurology and Neurosurgery. 2015;78(5):555-561.

Linch GF, Müller-Staub M, Moraes MA, Azzolin K, Rabelo ER. Cross-cultural adaptation of the Quality of Diagnoses, Interventions and Outcomes (Q-DIO) instrument into Brazilian Portuguese. International Journal of Nursing Knowledge. 2012;23(3):153-158.

Linch GF, Rabelo-Silva ER, Keenan GM, Moraes MA, Stifter J, Müller-Staub M. Validation of the Quality of Diagnoses, Interventions and Outcomes (Q-DIO) instrument for use in Brazil and the United States. International Journal of Nursing Knowledge. 2015;26(1):19-25.

Marečková J, Jarošová D. NANDA domény v posouzení a diagnostické fázi ošetřovatelského procesu. 1. vyd. Ostrava: Ostravská univerzita, Zdravotně sociální fakulta; 2005. (in Czech)

Marečková J, Klugarová J, Gurková E, Jarošová D, Klugar M, Zeleníková R. Evidence-based healthcare. Zdravotnictví založené na vědeckých důkazech. Olomouc: Univerzita Palackého v Olomouci; 2015. Available from:

http://cebhc.upol.cz/upload/soubory/monografie/ebhc_ekniha _2015.pdf (in Czech)

Marečková, J. Editorial. Central European Journal of Nursing and Midwifery. 2016;7(3):461.

Marini M, Chaves EH. Evaluation of the accuracy of nursing diagnoses in a Brazilian emergency service. International Journal of Nursing Terminologies and Classification. 2011;22(2):56-67.

Mateos-García MD, Müller-Staub M, Porcel-Gálvez A, GilGarcía E, Ramos-González-Serna A, Barrientos Trigo S. Questionnaire for the assessment of the Quality of Diagnoses, Interventions and Outcomes (Q-DIO). Cross-cultural adaptation to Spanish. In: Sheerin F, Sermeus W, Ehrenberg A, editors. E-health and nursing - knowledge for patient care: $10^{\text {th }}$ European conference of ACENDIO. Ireland: Dublin; 2015. p. 565-567. Available from: http://www.acendio.net/members/proceedings/ACENDIO201 5.pdf

Müller-Staub M, Needham I, Odenbreit M, Lavin MA, van Achterberg T. Improved quality of nursing documentation: results of a nursing diagnoses, interventions and outcomes implementation study. International Journal of Nursing Terminologies and Classifications. 2007a;18(1):5-17.

Müller-Staub M. Evaluation of the implementation of nursing diagnostics. A study on the use of nursing diagnoses, interventions and outcomes in nursing documentation. Dissertation. Bern: St. Radboud University; 2007b. Available from:

http://repository.ubn.ru.nl/bitstream/handle/2066/40179/4017 9.pdf?sequence $=1$

Müller-Staub M, Lunney M, Lavin MA, Needham I, Odenbreit M, van Achterberg T. Testing the Q-DIO as an instrument to measure the documented quality of nursing diagnoses, interventions and outcomes. International Journal of Nursing Terminologies and Classifications. 2008a;19(1):20-27.

Müller-Staub M, Needham I, Odenbreit M, Lavin MA, van Achterberg T. Implementing nursing diagnostics effectively: cluster randomized trial. Journal of Advanced Nursing. 2008b;63(3):291-301.

Müller-Staub M, Lunney M, Odenbreit M, Needham I, Lavin MA, van Achterberg T. Development of an instrument to measure the quality of documented nursing diagnoses, interventions and outcomes: the Q-DIO. Journal of Clinical Nursing. 2009;18(7):1027-1037.

Nomura ATG, da Silva MB, Almeida MdA. Quality of nursing documentation before and after the hospital accreditation in a university hospital. Revista LatinoAmericana de Enfermagem. 2016;24:e2813.

Nordström G, Gardulf A. Nursing documentation in patient records. Scandinavian Journal of Caring Sciences. 1996;10(1):27-33.

Odutayo PO, Olaogun AA, Oluwatosin AO, Ogunfowokan AA. Impact of an educational program on the use of standardized nursing languages for nursing documentation among public health nurses in Nigeria. International Journal of Nursing Knowledge. 2013;24(2):108-112.

Paans W, Müller-Staub M. Developing an international nursing documentation audit instrument: Expert consensus study. In: Sheerin F, Sermeus W, Ehrenberg A, editors. Ehealth and nursing innovating for the future: $9^{\text {th }}$ European conference of ACENDIO. Ireland: Dublin; 2013. p. 122-142. Available from:

http://www.acendio.net/members/proceedings/ACENDIO201 3.pdf

Paans W, Sermeus W, Nieweg RM, van der Schans CP. DCatch instrument: development and psychometric testing of measurement instrument for nursing documentation in hospitals. Journal of Advanced Nursing. 2010;66(6):13881400.

Polit DF, Tatano Beck C. Nursing research: Principles and methods. 7th ed. Philadelphia: Lippincott, Williams \& Wilkins; 2004.

Rabelo-Silva ER, Dantas Cavalcanti AC, Ramos Goulart Caldas MC, Lucena AF, Almeida MA, Linch GF, da Silva MB, Müller-Staub M. Advanced nursing process quality: 
comparing the International Classification for Nursing Practice (ICNP) with the NANDA-International (NANDA-I) and Nursing Interventions Classification (NIC). Journal of Clinical Nursing. 2017;26(3-4):379-387.

Seen S, Lötscher R, Müller-Staub M. Cross-cultural adaptation of the French version of the Q-DIO Instrument: model and preliminary findings. In F. Sheerin W. Sermeus A. Ehrenberg, editors. E-health and nursing - knowledge for patient care: $10^{\text {th }}$ European conference of ACENDIO. Ireland: Dublin; 2015. p. 291-293. Available from:

http://www.acendio.net/members/proceedings/ACENDIO201 5.pdf

Streiner DL, Norman GR. Health measurement scales: a practical guide to their development and use. 2nd ed. Oxford University Press, New York; 1995.
Wang N, Hailey D, Yu P. Quality of nursing documentation and approaches to its evaluation: a mixed-method systematic review. Journal of Advanced Nursing. 2011;67(9):18581875.

Zanon D, Gralher D, Müller-Staub M. Nursing diagnosis acute pain interventions and outcome: evaluation of patients' experience after total hip replacement compared with the nursing record - a mixed methods study. In: Sheerin F, Sermeus W, Ehrenberg A, editors. E-health and nursing knowledge for patient care: $10^{\text {th }}$ European conference of ACENDIO. Ireland: Dublin; 2015. p. 565-567. Available from:

http://www.acendio.net/members/proceedings/ACENDIO201 5.pdf 